\title{
Preface
}

\section{Recent Advances in Small Cell \\ and Non-Small Cell Lung \\ Cancer, Diagnosis, Staging, \\ and Surgical Treatment: A \\ Tribute to Jean Deslauriers}

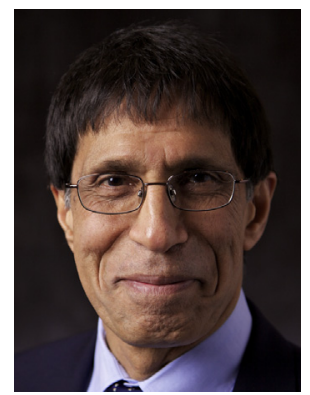

Farid M. Shamji, MBBS (UK),FRCSC, FACS

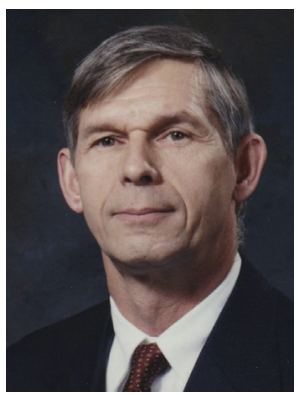

Gilles Beauchamp, MD, FRCSC

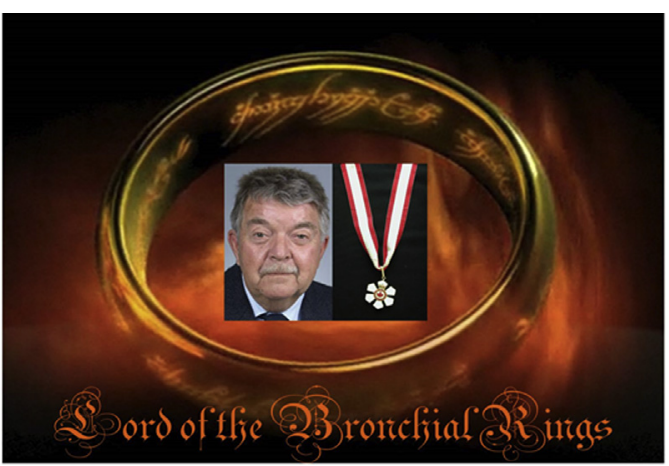

Dr Jean Deslauriers, MD, FRCSC(1945-2019)

Editors

On September 13, 2019, the thoracic surgical community lost a valued member when $\mathrm{Dr}$ Jean Deslauriers died after 40 years of practice, of the very disease that he spent lifetime studying and treating. He was regarded as a leader in the field of thoracic oncology and had a profound impact on the surgical teaching, clinical research, writing of scientific papers on lung cancer, career, and life of many of the authors of this 2-part issue on lung cancer.

Jean Deslauriers was a native of Quebec, was born on May 25, 1945, and was indebted to $\mathrm{Dr}$ Frederick Griffith Pearson, Dr Robert Jason Ginsberg, Dr Joel David Cooper, and Dr Bill Nelems. His friendship with them began in Toronto when he went to train at the Toronto General Hospital under these masters of Thoracic Surgery. His career began at the University of Laval when he returned to Quebec City. His interest in lung cancer prospered with an intense combination of surgical care and clinical research. Soon in his career he began publishing his results and experience. Early on, he became recognized as a leader in the surgical community. Then began a journey where Jean was invited to lecture on lung cancer in many countries, including France, China, Australia, South America, and North America.
Because of his personality, he made friends all over the world.

Lung cancer is a deadly disease, which kills over a million people annually; those numbers are more than breast, colon, and prostate cancer combined.

Major advances have been made in lung cancer in the last 40 years, with better understanding of the disease by surgeons and oncologists. Decline in cigarette smoking and early detection of cancer by low-dose computed tomography, earlier diagnosis, and advances in imaging staging with computed tomography and PET have all contributed to a better management of the disease. The treatment of lung cancer has also evolved, and therapeutic as well as palliative care has been modified through fundamental and clinical research.

It thus appears that the essential facts on lung cancer found in early texts are still important, but they have evolved and developed into a more refined biological science that must be well known if one is to ensure that each patient with lung cancer gets the best possible treatment. Indeed, most articles are written by thoracic surgeons, thoracic radiologists, and thoracic oncologists, who not only possess detailed knowledge of the disease and comprehend it but also were close friends or 
trainees of Dr Jean Deslauriers. This publication is to honor his memory.

Farid M. Shamji, MBBS (UK), FRCSC, FACS University of Ottawa

General Surgery, Vascular Surgery Cardiovascular and Thoracic Surgery General Thoracic Surgery 1 Burdock Grove Nepean, Ontario K2R 1A1, Canada
Gilles Beauchamp, MD, FRCSC Thoracic Surgery Unit Department of Surgery Maisonneuve-Rosemount Hospital University of Montreal 5415 L'Assomption Boulevard Montreal, Quebec H1T 2M4, Canada

E-mail addresses: faridshamji@hotmail.com (F.M. Shamji) Gilles.d.beauchamp@sympatico.ca (G. Beauchamp) 